\title{
Sufficiency inference in anankastic conditionals *
}

\author{
Sveta Krasikova \\ University of Tübingen
}

\begin{abstract}
The minimal sufficiency reading of anankastic conditionals, discussed in connection with Heim's (2001) ambiguities in comparative constructions and von Fintel \& Iatridou's (2007) 'Prejacent Problem' in the sufficiency modal construction, is argued to stem from the kind of ordering associated with anankastic modals.
\end{abstract}

Keywords: modals, anankastic conditionals, scales, sufficiency, ambiguity, comparatives.

\section{Introduction}

Goal-oriented modal statements like (1), dubbed anankastic conditionals (henceforth $\mathrm{AC}$ ), have been recently discussed within a possible worlds approach to modality in connection with the semantic role of the 'in order to' clause and its relation to the proposition embedded under the modal, see von Fintel \& Iatridou 2005 among others. Everyone seems to agree that the infinitival clause serves to determine the range of accessibile worlds quantified over by the modal, i.e. plays the role of the antecedent. Thus, in (1a) the necessity that the addressee take the A train arises in worlds making true the proposition that he/she goes to Harlem. It is, however, far from clear how the goal/means relation expressed by (1a) can be encoded, see Fernando 2005 for a discussion, and whether this relation is affected by or affects the interpretation of the modal. Below we shall briefly touch upon these two aspects to delineate the scope of this work.

(1) a. In order to go to Harlem, you have to take the A train.

b. In order to restart the printer, you have to press the button.

First, by virtue of expressing a means for achieving the goal contained in the antecedent, the proposition under the modal is sometimes understood to convey a condition sufficient for that goal. While in (1b) the action in the main clause is understood to be sufficient for the one in the 'in order' clause, (1a) is underspecified in this respect. Obviously, this kind of underspecification does not hinge on the

* We thank Vera Hohaus, Anna Howel, Remus Gergel and Polina Berezovskaya for an inspiring discussion and also the participants of SALT 20 for challenging questions. 
modal but is a general property of the goal/means relation, ${ }^{1}$ as the following variants of (1a) and (1b) without modals suggest.

a. You take the A train in order to go to Harlem.

b. You press the button in order to restart the printer.

Second, the role of the modal in pinning down the relationship between the 'in order to clause' and the proposition under the modal becomes crucial in scalar contexts where the choice of the modal auxiliary appears to determine the resulting interpretation. Consider the minimal pair in (3). While (3a) can refer to the minimal score required for winning the race, this reading is impossible in (3b). (3b) can only mean that the score was exceedingly high.

a. You scored more points than you had to in order to win.

b. You scored more (penalty) points than you ought to have in order to win.

Note that by virtue of referring to the minimally required amount (3a) talks about sufficiency, however, not on a propositional level as in (1b), i.e. in the sense of one action being sufficient for another, but rather on a degree level, i.e. in the sense of a degree of some property being sufficient for some action.

In a possible worlds approach to modals in the spirit of Kratzer 1981, the distinction between the goal-oriented 'have to' and 'ought to' would normally be captured by the type of the ordering source, a contextual parameter determining the accessibility relation on the modal, see von Fintel \& Iatridou 2005. This raises the question of whether and how the accessibility relation can influence the availability of the minimal sufficiency inference. This issue is the main concern of the present paper. We will not attempt to explain the 'propositional-level' sufficiency inference of AC apparently related to the fundamental question of how to spell out " $\mathrm{x}$ is a means for achieving $y$ ". We will take that meaning component for granted and focus on the property of AC to refer to the 'degree-level' sufficiency.

The structure of the paper is as follows. Section 2 has two objectives: we will consider a larger range of contexts with the minimal sufficiency inference (henceforth MS) and show that explaining the observed pattern under the standard analysis of goal-oriented modals is not straightforward. In section 3 we will recast the standard analysis of AC by using the notion of comparative possibility of propositions from Lewis 1973 to spell out the pragmatic reasoning leading to the MS. In section 4 we will focus on the cases when this reasoning fails to apply allowing for the optionality or the lack of the MS.

1 The nature of this relation has been much investigated in the AI literature on planning. The two relevant kinds goal/means relation are enablement and generation, see Balkanski 1993. 
Sufficiency inference in anankastic conditionals

\section{The minimal sufficiency inference}

Two kinds of MS contexts have caused much debate in the recent semantic literature on modality; however, they have never been discussed under this rubric nor related to each other. The first environment is the use of a numeral or a gradable property - more generally, any scalar expression - under an anankastic modal. Geurts 2006 points out that a numeral under 'have to' tends to receive an 'at least' reading corresponding to the MS reading, e.g. (4a). Furthermore, there is a whole array of comparative sentences which also have been observed to express comparison with a minimally sufficient degree. Sentences (4b) through (4d) are paradigmatic examples of such comparatives based on the data from Heim 2001, Heim 2006, and Stateva 2002. They all share a reading which talks about the minimally sufficient score. In (4b) the minimally sufficient score is claimed to be under 100 points; in (4c) it is claimed to be exactly 5 points more than some contextually provided amount; in (4d) the addressee is claimed to have the highest minimal requirement; and, finally, in (3a) the addressee's actual score is said to exceed the minimally sufficient score.

a. You have to score 100 points in order to win.

b. You have to score less than 100 points in order to win.

c. You have to score exactly 5 points more than that in order to win.

d. You have to get the highest score in order to win.

The term 'at least' reading appears not to be general enough since the numerical scale may happen to be the inverse of the 'sufficiency' scale, ${ }^{2}$ see example (5) where the numeral has an 'at most' reading. (5) conveys that getting after 5 a.m. is insufficient, i.e. too late, for catching the first train, and any time before 5 a.m. is more than minimally required. We can, of course, construct examples with time adverbials that have an 'at least' reading of the numeral, e.g. (6).

(5) You have to get up at 5 a.m. in order to catch the first train.

(6) You have to arrive at 12 o'clock to be able to check in.

As shown in Nouwen 2010, the fact that ' 100 points' in (4a) refers to the minimal requirement can be easily derived in von Fintel \& Iatridou's (2005) analysis of 'have to' as a universal quantifier over worlds restricted by an 'in order to' clause. All we need is to ensure that the numeral is assigned an 'at least' meaning, see (7), and that the plain meaning of the whole sentence is pragmatically enriched by adding the clause in (8).

$$
\begin{aligned}
& \forall w^{\prime} \in[\lambda w \text { you win in } w]: w^{\prime} \in[\lambda w \text { your score in } w \geq 100 \text { points }] \\
& \text { 'In all winning worlds you score at least } 100 \text { points.' }
\end{aligned}
$$

2 We use the term 'sufficiency' scale, which is to be defined in section 3 , in the intuitive sense. 
$\forall n>100: \exists w^{\prime} \in[\lambda w$ you win in $w]: w^{\prime} \notin[\lambda w$ your score in $w \geq n$ points $]$ 'There are winning worlds in which you do not score more than 100 points.'

There are, however, several important questions that this solution raises. First, it is unclear how the exhaustification solution can differentiate between 'have to' and other modals, like 'ought to', with which the MS inference is not possible. None of the examples of (4) with 'have to' replaced by 'ought to' can refer to the minimally sufficient score. Second, the 'at least' meaning assumption appears not only stipulatory, but it does not generalise to cases like (5), where one would have to work with an 'at most' meaning. In other words, the direction of the scale on which the exhaustification mechanism operates is not fixed, though one is left with the feeling that this direction is not context dependent but hinges on the interpretation of the sentence.

The second MS environment is the scope of 'only'. In this case, the scale is induced by 'only', which is traditionally treated as a scalar operator negating higher ranked alternatives to its propositional argument, called prejacent. von Fintel \& Iatridou (2007), who call AC embedded under 'only' the sufficiency modal construction, point out that they do not carry the 'prejacent presupposition' triggered by 'only'. They call this the Prejacent Problem. For example, (9a) does not presuppose that the addressee has to take the A train to go to Harlem. von Fintel \& Iatridou, however, neglect the fact that if the prejacent is compared to its alternatives according to their logical strength the problem does not arise. For example, (9b) is only felicitous if its prejacent is true. The difference between (9a) and (9b), which is apparently behind the lack of the 'prejacent presupposition', is that only the prejacent of the latter has an MS inference.

(9) a. In order to go to Harlem, you only have to take the A train.

b. In order to win you only have to score 100 points.

The goal of the next section is to track down the source of the MS inference in order to i) explain the asymmetry between 'have to' and 'ought to' in AC, and ii) find a solution to the Prejacent Problem. As suggested at the outset of the paper, we will tackle this task by focusing on the analysis of AC.

\section{Comparative semantics for anankastic modals}

As the discussion above makes clear, the MS inference is rooted in the scalarity of the relevant constructions. We argued that the simple exhaustification mechanism, though efficient, is an ad hoc solution. In what follows we will show that the semantics of anankastic modals provides an appropriate scale and a comparative relation to derive the MS inference without resorting to exhaustification. To give a 
preview of our proposal, we suggest that the 'sufficiency' scale corresponds to the possibility scale, in the sense of Lewis 1973 , used by a necessity modal to compare its propositional complement to alternative propositions. For example, the truth conditions of (4a) can be paraphrased as in (10).

(10) That the addressee achieves his/her goal to win and scores 100 points is a better possibility in $w$ than that he/she achieves his/her goal to win and gets $n$ points, where $n$ is a score different from 100 .

Two ingredients in (10) are noteworthy. First, the notion of comparative possibility is based on the relation of similarity to the index world. The criterion for deciding which of two propositions is a better possibility is their closeness to the world of evaluation. Second, the propositions compared to each other have a rigid form varying in the place of the numeral. In the given example, we compare the possibility of a proposition based on the addressee's score. The worlds closest to $w$ are those where the addressee wins and nothing unusual from the perspective of $w$ happens. A far-fetched world could be a world in which the addressee wins without a sufficient score as well as a world in which the addressee takes too much effort. If we reason like this, (10) is met iff scoring 100 points is minimally sufficient for winning. This is how the MS inference comes about. In what follows we will provide independent motivation for the assumptions underlying (10), namely, similarity to the evaluation world as a type of ordering employed by anankastic modals and the use of alternatives.

\subsection{Anankastic conditionals as counterfactuals}

Taking for granted the status of the 'in order to' clause as a domain restrictor of an anankastic modal, let us adopt von Fintel \& Iatridou's (2005) Kratzer-style proposal for the semantics to an AC, outlined in (11).

(11) 'To $p$, have to $q$ ' is true relative to modal base $f(w)$ iff all the worlds in $f(w)$ where $p$ is achieved are $q$-worlds.

We refrain here from the discussion of what it means for $p$ be a goal of $q$, which is obviously needed for spelling out ' $p$ is achieved', since this relates to the interpretation of rationale clauses rather than that of 'have to'. It is more of a concern to us how the value of $f(w)$ is determined. A number of authors assume that anankastic modals are associated with a circumstantial modal base, see von Fintel \& Iatridou 2005 and Huitink 2005. For example, von Fintel \& Iatridou (2005) suggest that 'have to' in sentence (1a) is evaluated relative to $f$ that includes circumstances related to the goal of getting to Harlem, such as the location of the addressee, relevant train schedules and other facts related to the transportation system. Those facts have to 
hold in the worlds over which 'have to' quantifies. Suppose, only the A train stops in Harlem, then, given that $f(w)$ contains the worlds in which the relevant circumstances hold, the truth conditions in (11) correctly predict that (1a) is true in this situation.

As reasonable as it might appear, positing a circumstantial modal base for AC is called into question in von Stechow, Krasikova \& Penka 2006. They note that it is not clear which facts count as relevant and should be included in the modal base. Even "circumstances related to the salient goal" is a far too vague definition to pin down the kind of facts that restrict an anankastic modal.

"There are many ways to go to Harlem. You can take the A train, you can take a taxi, you can ask someone to give you a ride, you can walk all the way through Manhattan, you can even pretend to be an emergency and call for the ambulance. In other words, the facts are that you will reach Harlem, by taking the A train, by walking through Manhattan and so on. [...] So how do we know that of all these facts the only thing that matters is that you will reach Harlem if you take the A train? We think the answer is that taking the A train is the easiest way to get to Harlem. The other ways mentioned are more remote possibilities. So we really need a theory that chooses the least remote possibility among several possibilities." (von Stechow et al. 2006)

To account for the intuition that remote possibilities leading to the achievement of a goal are ignored, von Stechow et al. (2006) propose to treat AC as Lewisonian variably strict conditionals. Such a treatment was applied to the analysis of counterfactual conditionals in Lewis 1973 and later in Kratzer 1981. The main idea is that possible worlds can be ordered relative to how much they depart form the ideal represented by the world of evaluation.

Following von Stechow et al. (2006), we treat AC as counterfactuals. To keep track of the assumptions so far, let us formulate this proposal in Kratzer's framework. To capture Lewis's insight that the truth of a counterfactual depends on the relation of similarity to the actual world, Kratzer (1981) suggests that a counterfactual modal induces an ordering on the set of accessible worlds ranking them according to how remote they are from the index world. This ordering takes the form of an ordering source parameter defined as a function that assigns to any world a set of propositions that characterise it uniquely. Kratzer calls this kind of ordering totally realistic.

(12) A totally realistic conversational background is a function $g$ such that $\forall w \in W: \bigcap g(w)=\{w\}$

The set of propositions assigned to a world by an ordering source induces a partial 
Sufficiency inference in anankastic conditionals

ordering on the set of possible worlds $\mathrm{W}$ in the following way.

$$
\forall w, w^{\prime}: w \succeq_{g(w)} w^{\prime} \text { iff }\left\{p: p \in g(w) \wedge w^{\prime} \in p\right\} \subseteq\{p: p \in g(w) \wedge w \in p\}
$$

Integrating a totally realistic ordering into von Fintel \& Iatridou's (2005) rule proceeds as shown in (14). The modal base $f(w)$, does not contribute any further restriction on the accessible worlds and is therefore assumed to be empty.

(14) 'To $p$, have to $q$ ' is true relative to a totally realistic ordering source $g(w)$ and an empty modal base $f(w)$ iff all the worlds in $f(w)$ that make as many propositions from $g(w)$ true as possible and where $p$ is achieved are $q$-worlds.

As intended, this analysis overcomes the problem of 'remote possibilities' addressed in von Stechow et al. 2006. Consider a scenario in which only the A train stops in Harlem. For any world in which the addressee achieves the goal of getting to Harlem by such expensive or time-consuming means as taking a taxi or walking all the way through there is a closer world in which he/she reaches Harlem on the A train. Even more remote are the worlds in which the addressee gets to Harlem on a different train, given the transportation system.

\subsection{Alternatives}

Consider the following context. Müller has to negotiate with Schmidt. He can meet Schmidt in Hamburg or Stuttgart. He may only drive or travel by train. He can get to Stuttgart by train, but there are no trains to Hamburg that depart early enough for Müller to make it to the meeting. Uttered in such situation, sentence (15a) with the focus on the directional PP is judged false. Driving to Stuttgart to meet Schmidt is as good a possibility given the facts as driving to Hamburg. The sentence, however, becomes true if we switch the focus from 'Hamburg' to 'drive', as in (15b).

a. To meet Schmidt, Müller has to drive to $[\text { Hamburg }]_{F}$.

b. To meet Schmidt, Müller has to [drive $]_{F}$ to Hamburg.

As shown in Dretske 1972 for a number of attitude predicates, a change in the focus structure has an impact on the truth of an attitude report. Obviously, modals like 'have to' are also sensitive to the focus structure of their complements. Intuitively, we compare possibilities of different propositions depending on what is at issue, or in other words, what are their salient alternatives. In (15a) driving to Hamburg is compared to driving somewhere else, while in (15b) it is compared to getting to Hamburg by some other means. This has to be reflected in the interpretation of AC.

A straightforward way to define an alternative semantics for AC becomes apparent if we reformulate the meaning adopted in the previous section, using the relation 
of comparative possibility, an alternative way to formulate the truth conditions of a counterfactual due to Lewis 1973. For convenience, we use Kratzer's (1981) definition of comparative possibility, which is equivalent to Lewis's (1973).

(16) A proposition $p$ is more possible than a proposition $q$ in a world $w$ in view of a modal base $f$ and an ordering source $g$ iff
a. $\forall u \in(\bigcap f(w) \cap q): \exists v \in \bigcap f(w): v \succeq_{g(w)} u \wedge v \in p$.

b. $\exists u \in(\bigcap f(w) \cap p) \wedge \neg \exists v \in(\bigcap f(w) \cap q): v \succeq_{g(w)} u$.

Lewis (1973) shows that this modal relation can be used to formulate the truth conditions of a conditional with antecedent $k$ and consequent $r$ in the following way.

(17) A proposition that $k$ and $r$ is more possible than a proposition that $k$ and not $r$ in a world $w$ in view of a modal base $f$ and an ordering source $g$.

Since Kratzer's (1981) truth conditions of counterfactual conditionals are equivalent to Lewis's (1973), ${ }^{3}$ we may safely recast the truth conditions for AC adopted above in terms of comparative possibility. ${ }^{4}$ This gives us with the following meaning rule for $\mathrm{AC}$.

'To $p$, have to $q$ ' is true in $w$ relative to a totally realistic ordering source $g(w)$ and an empty modal base $f(w)$ iff [that $p$ is achieved and $q$ ] is more possible in $w$ than [that $p$ is achieved and not $q$ ] in view of $g(w)$ and $f(w)$.

According to this rule, a counterfactual conditional compares possibilities of two propositions relative to what is the case in the actual world. More specifically, it relates the possibility of the conjunction of its complement with the antecedent to the possibility of the conjunction of its complement with the negation of the antecedent. This semantics lends itself perfectly to the introduction of alternatives.

'To $p$, have to $q$ ' is true in $w$ relative to a totally realistic ordering source $g(w)$ and an empty modal base $f(w)$ iff $\forall k \in g(C)$ : [that $p$ is achieved and $q$ ] is more possible in $w$ than [that $p$ is achieved and $k$ ] in view of $g(w)$ and $f(w)$.

Let us turn back to the examples in (15), where this revision is crucial. Abstracting away from the details of focus evaluation, let us simply assume that the alternatives correspond to the focus semantic value of the complement of 'have to'. The focus semantic value of a constituent is a set of meanings matching the semantic type

3 See Lewis 1981 for a proof.

4 To be precise, Lewis's and Kratzer's formulations based on comparative possibility depart from the truth conditions introduced in the previous section in that they do not make the so called Limit Assumption, i.e. they do not presuppose the existence of the closest worlds. This distinction is not crucial for the present purposes: we made the Limit Assumption in (14) for the sake of perspicuity. 
Sufficiency inference in anankastic conditionals

of this constituent, formed by abstracting over the value of the focused element, see Rooth 1985. In (15a) the alternatives vary in the place of the focused locative $\mathrm{PP}$, while in (15b) the focused phrase is a verb of motion, the alternatives therefore involve different means of reaching Hamburg. Given this, we derive by rule (19) that (15a) is true iff Müller's driving to Hamburg and meeting Schmidt is a better possibility in view of what is case than that his driving anywhere else and achieving the same goal. This condition is not met in the given scenario: driving to Stuttgart is as good a possibility as driving to Hamburg. On the other hand, (15b) is predicted true iff Müller's driving to Hamburg and meeting Schmidt is a better possibility than his getting to Hamburg by any other transportation means. This is the case in the given situation, which is a desired outcome.

\subsection{Scalar cases}

Let us show that the analysis of AC adopted above predicts the availability of the MS inference in scalar contexts. Turning back to example (4a), it is plausible to assume that it compares the possibilities to win by scoring a certain number of points. The derived truth conditions are given in (20).

$\forall k \in\{$ [that you get $n$ points]: $n \in \mathbb{N} \wedge n \neq 100\}:$ [that you win and get 100 points] is more possible in $w$ in view of $g(w)$ than [that you win and $k$ ]]

Suppose that the addressee is taking part in a final race of a championship. Given his score so far, 100 points - the minimal score one receives by finishing a race — suffice for him to win the championship. Due to a big advantage over other participants, he can achieve his goal by taking the minimal effort. Given these facts, the ordering source contains at least the following two propositions:

$\mathrm{g}(\mathrm{w})=\{$ that the addressee chooses the easiest means to achieve his goal, that the minimal score sufficient for winning is 100 points, ... $\}$

To see whether the truth conditions in (20) are met in the scenario at hand we compare getting 100 points and winning to getting more or less than 100 points and winning. Taking into account the fact that 100 points is the minimal requirement, the addressee's winning by getting less than 100 points is much more remote than his winning by getting 100 points. Likewise, winning with a score greater than 100 points is a more remote possibility than winning with 100 points given the fact that it requires more effort from the addressee. Therefore, sentence (4a) is correctly predicted true. It is obvious that for no score $n$ different from the minimally sufficient score is a sentence of the form 'you have to score $n$ points in order to win' true under this analysis. 100 points can therefore only refer to that degree. 
Let us explicate the source of the MS inference in general terms. It comes about in contexts which make salient an effort scale measuring difficulty or cost of actions in view of a given goal. Often this scale is mapped to the numerical scale associated with a degree-denoting expression. In the example at hand, the greater the score is, the more difficult it is to get it. We normally add the preference for the easiest way to achieve one's goals to the factual background that corresponds a totally realistic ordering source associated with the anankastic 'have to'. Therefore the relative possibility of a proposition is partially determined by the measure of effort it involves. This has the effect that the complement of 'have to' is understood to be the easiest means leading to the goal. Looking back at (4a), by virtue of being the easiest way to win, scoring 100 points renders all easier alternatives, i.e. scoring less than 100 points, insufficient and all more difficult ones, i.e. scoring more than 100 points, as unnecessary, as schematised in below.

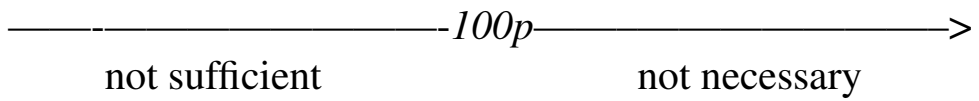

This is not to say that we have shown that getting 100 points is sufficient for winning on a propositional level. We have rather shown that doing something as difficult as getting 100 points is sufficient. Importantly, we do not use the numerical scale to estimate comparative possibilities of propositions, but associate it with an effort scale. The effort scale and the numerical scale may turn out to be inverse. This is the case in example (5). Given the world knowledge, the earlier one gets up the more effort is involved. Therefore, getting at 5 a.m. performs the following partition on its alternatives:

$-5 a . m . \longrightarrow$ not sufficient $>$

As a result, we understand (8) as conveying that getting up after 5 a.m. is insufficient and getting up before that time is unnecessary.

Naturally, the MS inference obtains in comparatives and under 'only'. For example, in (3a) we deal with a bound degree variable in the scope of 'have to' instead of a measure phrase as in (4a). The bound variable gets the value of the minimally required score, see (22), and the addressee's actual score is claimed to exceed whatever that degree corresponds to.

(22) $\quad \lambda d \forall k \in\{$ [that you get $n$ points]: $n \in \mathbb{N} \wedge n \neq d\}$ : [that you win and get $\mathrm{d}$ points] is more possible in $w$ in view of $g(w)$ than [that you win and $k$ ]] $=$ $\lambda d \forall d^{\prime} \neq d$ : [that you win and get $d$ points] is more possible in $w$ in view of $g(w)$ than [that you win and get $d^{\prime}$ points]. 
Similarly, the use of 'only' in (9a) induces an ordering on the alternatives to its prejacent. It is plausible that for reasons of economy this ordering is mapped to the effort scale employed by the anankastic modal as shown in (23a). The alternatives excluded by 'only' are therefore understood to involve more effort than that expressed by the prejacent, see (23b), and by virtue of being presupposed the prejacent is conveyed to involve the minimally sufficient amount of effort, see (23c).

a. $\forall a, b: a=$ [that to $p$ you have to $q$ ] $\wedge b=$ [that to $p$ you have to $q^{\prime}$ ]: $a>_{R} b$ iff $q$ involves more effort than $q^{\prime}$.

b. $\forall k>_{R}$ [that to go to Harlem you have to take the A train]: not $k(w)$.

c. For any salient alternative $k$ : [that you take the A train and achieve your goal to get to Harlem is a better possibility in view of what is the case than [that $k$ and you achieve your goal to get to Harlem].

This analysis renders the semantic contribution of 'only' trivial, since the prejacent already expresses the claim that the more difficult alternatives are unnecessary. We take this to be a satisfactory result and suggest that the role of 'only' in the sufficiency modal construction is reduced to its 'diminishing' function. Like other exclusive particles, it ranks its prejacent low on the relevant scale. In the example at hand, taking the A train is conveyed to be easy.

The present analysis can cope with the Prejacent Problem, i.e. the apparent lack of the 'prejacent presupposition' in (9a). The source of the problem is the choice of a set of alternatives with respect to which the prejacent of 'only' is evaluated. Only if this choice matches the set of alternatives selected by 'only' does the inference from (9a) to its prejacent hold. However, to evaluate a non-scalar prejacent, we tend to opt for an unranked set of alternatives to the complement of the the modal, whereas, in the presence of 'only', the alternatives are always ranked on the effort scale. More concretely, (1a), the prejacent of (9a), is naturally evaluated in a context where the alternatives to taking the A train are compared relative to whether they lead to Harlem. In contrast, (9a) is only felicitous in a context in which such alternatives are compared relative to how much effort they involve.

In a scalar case, the ranking on the set of alternatives is imposed lexically and the role of the context is secondary. We therefore expect that both the sufficiency modal construction and its prejacent are interpreted with respect to the same ordered set of alternatives and the Prejacent Problem does not arise. This is indeed the case in (9b).

\section{Distribution of the minimal sufficiency inference}

To sum up our findings so far, the MS inference results from mapping a lexically provided scale, e.g. a scale associated with a gradable predicate or a numeral, to an 
effort scale which, if made prominent in a context, is crucial for comparing different ways of a achieving a goal on a possibility scale contributed by an anankastic modal. The MS inference is therefore pragmatically rather than semantically anchored. In this section we will demonstrate how the context can influence the availability of the MS inference. We will distinguish two interfering pragmatic factors. First, the mapping of a lexical scale to an effort scale may be hindered by what counts as difficult in the context. Second, the effort scale may not play a role in estimating the relative possibility of a proposition.

In section 4.1 we will focus on the cases of ambiguity in comparatives and argue that they result from the optional dependence of the effort scale on the lexical scale, the first interfering pragmatic factor. Section 4.2 is concerned with the 'ought to'-like modals and reduces the absence of the MS reading in such cases to the lack of dependence of the possibility scale on the effort scale, the second factor.

\subsection{Fixing the effort scale}

Heim (2001) identifies two kinds of ambiguous comparatives with anankastic modals: comparatives with 'exactly' differential phrases, e.g. (24a), and 'less' comparatives, e.g. (24b). To these we may add superlatives, discussed in Stateva 2002, e.g. (24c). Each of these examples may refer to the MS length, but does not have to. For example, (24a) either conveys that the minimally required length of the paper is 15 pages or that the paper can only be accepted if it is 15 pages long.

(24) a. (The draft is 10 pages long.) In order to be accepted, the paper has to be exactly 5 pages longer than that.

b. (The draft is 10 pages long.) In order to be accepted, the paper has to be less long than that.

c. In order to be accepted, your paper has to be the longest.

The analysis presented above can straightforwardly account for the MS readings of these examples. Each of them is based on the template 'the paper has to be $d$ pages long', i.e., features a degree term in the scope of 'have to'. The derived truth conditions, sketched in (25) below, predict that in each case that $d$ may refer to the length minimally sufficient for the paper to be accepted. Suppose that the context makes prominent an effort scale which can be mapped to the length scale, e.g. the longer your paper is, the more effort it has cost you to finish it. In this context, $d$ is understood to be the minimal requirement: other lengths are either below or above the minimum. In addition, (25a) requires that $d$ exceed the length of the draft by exactly 5 pages, (25b) requires that $d$ be less than 10 pages, and (25c) requires that 
Sufficiency inference in anankastic conditionals

the minimal requirement for all other salient papers be smaller than $d .^{5}$

a. $\forall d^{\prime} \neq d$ : [that $\mathrm{p}$ is accepted and $d \mathrm{pp}$ long, where $d=10+5$ ] is more possible in $w$ relative to $g(w)$ than [that $\mathrm{p}$ is accepted and $d^{\prime} \mathrm{pp}$ long].

b. $\forall d^{\prime} \neq d$ : [that $\mathrm{p}$ is accepted and $d$ pp long, where $d<10$ ] is more possible in $w$ relative to $g(w)$ than [that $\mathrm{p}$ is accepted and $d^{\prime} \mathrm{pp}$ long, where $\left.d^{\prime}<10\right]$.

c. $\forall d^{\prime} \neq d$ : [that $\mathrm{p}$ is accepted and $d \mathrm{pp}$ long, where $d$ is s.t. no other salient paper is required to be $d^{\prime \prime}$ pp long and $d^{\prime \prime}>d$ ] is more possible in $w$ relative to $g(w)$ than [that $\mathrm{p}$ is accepted and $d^{\prime} \mathrm{pp}$ long, where $d^{\prime}$ is s.t. no other salient paper is required to be $d^{\prime \prime}$ pp long and $d^{\prime \prime}>d^{\prime}$ ].

How does the second set of readings for the examples in (24) come about? We suggest that they surface in a context in which the effort scale cannot be identified with the length scale. In (24a), the use of 'exactly' may influence what counts as difficult in the context. It may signal that the difficulty resides in submitting the exact number of pages, not in writing a long paper. In that case (24a) amounts to saying that achieving the goal by any length different from 15 pages is more remote from the actuality for lack of precision. This is the second, non-MS reading for this sentence. Similar considerations apply to the other two examples. Given an appropriate pragmatic setting, (24b) and (24c) may mean that the exact requirement on the length of the paper is below the length of the draft or that the exact requirement on no other paper is as high.

The form of alternatives with respect to which an AC is evaluated may suggest how the effort scale is fixed. For example, the focus on 'less' in (24b) is incompatible with the MS reading. The truth conditions in (26) correspond to this option. Comparing writing less than 10 pages to writing as many as 10 may be appropriate in a context in which the difficulty resides in the ability to shorten the draft.

(26) [That $\mathrm{p}$ is accepted and $d \mathrm{pp}$ long, where $d<10$ ] is more possible in $w$ relative to $g(w)$ than [that $\mathrm{p}$ is accepted and $d^{\prime} \mathrm{pp}$ long, where $d^{\prime} \geq 10$ ].

Similarly, the focus on the 'the longest' in (24c) results in the truth conditions that do not trigger the MS inference, see (27). According to these truth conditions, the paper can only be excepted if its length exceeds the lengths of other salient papers. This can only be appropriate in a context, in which the difficulty resides in surpassing

5 For ease of exposition, in (25c) we do not spell out the meaning of the modal that is assumed to be part of the implicit restriction on the superlative. 
other candidates.

(27) [That $\mathrm{p}$ is accepted and $d \mathrm{pp}$ long, where $d$ is s.t. no other salient paper is required to be $d^{\prime \prime}$ pp long and $\left.d^{\prime \prime}>d\right]$ is more possible in $w$ relative to $g(w)$ than [that $\mathrm{p}$ is accepted and $d^{\prime} \mathrm{pp}$ long, where $d^{\prime}$ is s.t. some other salient paper is required to be $d^{\prime \prime}$ pp long and $\left.d^{\prime \prime}>d\right]$.

To conclude, the context determines the availability of the MS inference by providing the information about what counts as difficult. We have discussed some strategies for manipulating the effort scale. It can be influenced by the use of lexical items such as 'exactly' and by means of focus.

\subsection{Weak anankastic conditionals}

Another class of AC lacking MS readings are cases where the possibility scale associated with the modal does not depend on the effort scale. This is often the case in the absence of a lexical scale, i.e. in a non-scalar environment. In section 3.3 we concluded that the lack of alternatives ranked on the effort scale is the source of the Prejacent Problem. The effort scale does not always have to be inferred from the context for the interpretation of an AC. In a basic case, the comparative possibility is determined by whether the suggested means leads to the relevant goal. The context may but need not add the measure of effort as a factor determining how possible a proposition is. The presence of a scalar-item usually highlights the role of the effort scale. There is, however, an exception to this tendency, namely AC with 'ought to' and other modal auxiliaries marked by the subjunctive morphology. They never trigger an MS inference.

The variety of AC that block the MS inference are descriptively characterised by a seemingly weaker modal force. Consider the following pair of sentences from von Fintel \& Iatridou 2008. Obviously, the first sentence is false in the given scenario, while the second is true. We will follow von Fintel \& Iatridou (2008) in calling modal auxiliaries marked by the subjunctive weak modals.

(28) Imagine that to cross Siberia to go to Vladivostok you can take two trains: the Russian and the Chinese train. The Chinese train is more comfortable.

a. To go to Vladivostok, you have to take the Chinese train.

b. To go to Vladivostok, you ought to take the Chinese train.

To account for the absence of the MS inference with weak AC we suggest to treat them as involving two layers of modality. The proposal amounts to the following two claims: a) weak AC involve a high abstract propositional attitude and an embedded anankastic modal; b) the modal auxiliary in a weak AC is a spell out of an anankastic 
modal. It carries an uninterpretable feature 'subjunctive' which is licensed by a corresponding interpretable feature on the abstract attitude.

To elaborate the proposal, let us consider example (28b). We assume that the LF of this sentence features two modal operators. The low anankastic modal is realised as 'ought to' and the high modal ATT is an abstract propositional attitude. In (29) we give a skeleton of the LF.

\section{ATT [ought to [you take the Chinese train]]}

The role of subjunctive morphology in weak AC becomes transparent under the view of the subjunctive as a morphological feature, advocated in von Stechow \& Grønn 2009 for German. von Stechow \& Grønn (2009) develop a morphological feature system in which subjunctive morphology on a verb stem is treated as an uninterpretable feature [uSub] that needs to be licensed by a corresponding interpretable feature [iSub] carried by some element higher up in the structure. Since German subjunctive forms are not possible in matrix contexts, apart for some exceptional cases, they propose that subjunctive should be licensed by an attitude predicate. It is plausible to assume that subjunctive morphology on a weak anankastic modal also corresponds to an uninterpretable feature which must be licensed by an attitude. In the present set-up, this boils down to providing 'ought to' with the feature [uSub] and treating ATT as its licenser carrying the feature [iSub], as sketched below.

$$
\operatorname{ATT}_{[i S u b]}[\text { ought to }[\text { uSub] }[\text { you take the Chinese train]] }
$$

While 'ought to' is responsible for the anankastic modality and is analyzed along the lines of the anankastic 'have to', the interpretation of ATT is not so straightforward. The kind of the modal flavour ATT may express seems to be lexically anchored in the modal auxiliary it embeds, which is reflected in the meaning differences between various weak AC. We will not delve into a discussion of the subtle distinctions between 'should' and 'ought to'. For the sake of the given example, we may assume that ATT is a necessity modal quantifying over worlds that come as close as possible to what is recommended or wished by the speaker, i.e. it requires an ordering source of the kind given in (31).

$\mathrm{g}^{*}(\mathrm{w})=\{p: p$ corresponds to the speaker's wishes and recommendations to the addressee in $w\}$

Let us now consider the impact of embedding an anankastic modal under ATT on

6 We do not make any commitments as to how the 'in order to' clause is composed with the rest of the sentence and for simplification leave it out in this example. 
the truth conditions of an AC.

$\lambda w \forall w^{\prime}$ s.t. $w^{\prime}$ makes as many propositions from $\mathrm{g}^{*}(\mathrm{w})$ true as possible: $\forall k \in$ $g(C) \wedge k \neq$ [that the addressee takes the Chinese train]: [that the addressee takes the Chinese train and achieves his/her goal to go to Vladivostok] is more possible in view of a totally realistic $g\left(w^{\prime}\right)$ than [that the addressee takes the Chinese train and $k]$.

The first welcome prediction of this analysis is the apparent weakening of the modal force in weak AC. The higher ATT shifts the interpretation of the embedded anankastic modal to a different index. As a result, 'ought to' quantifies over a set of worlds that come closest to the ideal determined by ATT. This set is different from the quantification domain of the anankastic 'have to' in example (28a), where the actual world serves as an ideal. Hence, the following discourse is not contradictory.

To go to Vladivostok, you ought to take the Chinese train but you don't have to.

Second, this analysis offers a straightforward explanation for the lack of the MS inference. We argued that the crucial factor for the availability of MS is a totally realistic ordering associated with AC. Among the propositions that a modal, like 'have to' uses for ordering its propositional alternatives may be the fact that one picks the easiest, cheapest, fastest means to achieve one's goal. If an effort scale is prominent in a context, this consideration is employed for ranking propositions according to how remote they are from the actual world. Crucially, embedding an anankastic modal under ATT shifts the index at which the modal is evaluated. Thus, according to (32), it is not the possibility of a proposition in the actual world that is at issue but the possibility of a proposition in a world where the addressee follows the recommendations of the speaker. In such a world the considerations of cost and effort are not taken into account. As a result, being low on an effort scale does not necessarily rank a proposition as a good possibility. For concreteness, consider the minimal pair in (34).

a. To fulfill your course duties, you have to correct some of the exams.

b. To fulfill your course duties, you ought to correct some of the exams.

On its natural interpretation, (34a) compares the possibility that the addressee fulfills his/her duty by correcting some of the exams, given the facts, to the possibility that she/he does so by correcting all of the exams or correcting none. In (34b) a similar comparison may be made but the possibilities are evaluated relative to the preferences/wishes/recommendations of the speaker or some other salient individual, not relative to the facts. Whereas the former kind of comparison may create the 
Sufficiency inference in anankastic conditionals

inference that correcting some of the exams is the easiest way for the addressee to fulfil his/her course duties, this is unlikely with the second kind of comparison, for which the considerations of time, effort and the like are irrelevant. The addressee rather infers that correcting some of the exams must in some way be an optimal way to satisfy the relevant goal and somebody's preferences. The MS inference is therefore possible only in (34a).

\section{Conclusion}

We argued that the minimal sufficiency inference observed in AC is a pragmatic inference inherent to this kind of modality rather than a contribution of scalar expressions in whose presence it usually arises. The main claim of the paper is that positing a totally realistic ordering source for anankastic modals not only overcomes the problem of remote possibilities addressed in von Stechow et al. 2006 but also gives an adequate characterisation of the behaviour of such modals in scalar environments. The central idea is that an anankastic modal compares possibilities of achieving a goal by this or that means, given the facts, and in doing so can make use of a contextually provided effort scale. The MS inference amounts to understanding the uttered means for achieving the goal as involving the minimal effort. It is blocked in a context that does not provide an appropriate effort scale or in a weak AC as a result of embedding an anankastic modal under an abstract propositional attitude. This approach to the MS readings of AC gives us a handle on the notorious ambiguities in comparatives and superlatives with anankastic modals and the so called Prejacent Problem in the sufficiency modal construction.

\section{References}

Balkanski, Cecile Tiberghien. 1993. Actions, beliefs and intentions in multi-action utterances. Cambridge, MA, USA: Havard University dissertation.

Dretske, Fred. 1972. Contrastive statements. Philosophical Review 81(4). 411-437. doi:10.2307/2183886.

Fernando, Tim. 2005. Comic relief for anankastic conditionals. In P. Dekker \& M. Franke (eds.), Proceedings of the 15th Amsterdam Colloquium, 71-76. Amsterdam: University of Amsterdam.

von Fintel, Kai \& Sabine Iatridou. 2005. What to do if you want to go to Harlem: Anankastic conditionals and related matters. Ms.

von Fintel, Kai \& Sabine Iatridou. 2007. Anatomy of a modal construction. Linguistic Inquiry 38(3). 445-483. doi:10.1162/ling.2007.38.3.445.

von Fintel, Kai \& Sabine Iatridou. 2008. How to say Ought in foreign: The 
composition of weak necessity modals. In J. Guéron \& J. Lecarme (eds.), Time and modality, 115-141. Springer.

Geurts, Bart. 2006. Take "five": The meaning and use of a number word. In S. Vogeleer \& L. Tasmowski (eds.), Non-Definiteness and Plurality, 311-329. Amsterdam/Philadelphia: Benjamins.

Heim, Irene. 2001. Degree operators and scope. In C. Féry \& W. Sternefeld (eds.), Audiatur vox sapientiae. a festschrift for Arnim von Stechow, 214-239. Akademie Verlag.

Heim, Irene. 2006. Remarks on comparative clauses as generalized quantifiers. Ms. Huitink, Janneke. 2005. Proceedings of Conslole 13. In S. Blaho, L. Vicente \& E. Schoorlemmer (eds.), Analyzing anankastic conditionals and sufficiency modals, 135-156. University of Leiden.

Kratzer, Angelika. 1981. The notional category of modality. In H. J. Eikmeyer \& H. Rieser (eds.), Words, worlds, and contexts, 38-74. Berlin: de Gruyter.

Lewis, David. 1973. Counterfactuals. Oxford: Basil Blackwell.

Lewis, David. 1981. Ordering semantics and premise semantics for counterfactuals. Journal of Philosophical Logic 10(2). 217-234. doi:10.1007/BF00248850.

Nouwen, Rick. 2010. Existential needs? The semantics of minimal and maximal requirements. Ms.

Rooth, Mats. 1985. Association with focus: University of Massachusetts at Amherst dissertation.

Stateva, Penka. 2002. How different are different degree constructions: University of Connecticut dissertation.

von Stechow, Arnim \& Atle Grønn. 2009. The (non-)interpretation of subordinate tense. Ms.

von Stechow, Arnim, Sveta Krasikova \& Doris Penka. 2006. Anankastic conditionals again. In T. Solstad, A. Grønn \& D. Haug (eds.), A Festschrift for Kjell Johan Sab $\phi, 151-171$. Oslo: University of Oslo.

Sveta Krasikova

28 Walsh Road

Dublin 9

Ireland

contact@svetakrasikova.eu 